\title{
Comment on evidence for surface-initiated homogeneous nucleation
}

\author{
J. E. Kay ${ }^{1}$, V. Tsemekhman ${ }^{2}$, B. Larson ${ }^{1}$, M. Baker ${ }^{1}$, and B. Swanson ${ }^{1}$ \\ ${ }^{1}$ Department of Earth and Space Sciences, University of Washington, Seattle, USA \\ ${ }^{2}$ Applied Physics Laboratory, University of Washington, Seattle, USA
}

Received: 4 April 2003 - Published in Atmos. Chem. Phys. Discuss.: 1 July 2003

Revised: 12 September 2003 - Accepted: 12 September 2003 - Published: 22 September 2003

\begin{abstract}
We investigate theoretical, laboratory, and atmospheric evidence for a recently proposed hypothesis: homogeneous ice nucleation initiates at the surface, not in the volume, of supercooled water drops. Using existing thermodynamic arguments, laboratory experiments, and atmospheric data, we conclude that ice embryo formation at the surface cannot be confirmed or disregarded. Ice nucleation rates measured as a function of drop size in an air ambient could help distinguish between volume and surface nucleation rates.
\end{abstract}

\section{Introduction}

In a recent commentary, Tabazadeh (2003) suggested volume nucleation rates for large droplets cannot be extrapolated to predict nucleation rates for sub-micron stratospheric aerosols. Here, we comment on the basis for this argument, namely the referenced articles (Tabazadeh et al., 2002a,b) which provide "both experimental and theoretical support for the formation of the nucleus on the surface of the supercooled droplets" and lead to the conclusion that "freezing in particles most likely initiates at the surface layer".

The mechanisms and processes that control phase transitions from liquid water to ice affect many atmospheric processes including radiative transfer and chemical reaction rates. Homogeneous nucleation rates have traditionally been based on nucleation initiated in the volume of supercooled water drops (Pruppacher and Klett, 1997). If homogeneous nucleation initiates at the surface, as proposed by Tabazadeh et al. (2002a,b), nucleation rates have different drop size and temperature dependences, and therefore, predict different distributions of ice in the atmosphere (Fig. 1).

Correspondence to: J. E. Kay

(jenkay@u.washington.edu)
Theoretical and thermodynamic justification, reinterpretation of laboratory data, and comparisons to atmospheric observations have been used to support the hypothesis that freezing initiates on the surface of supercooled water (Tabazadeh et al., 2002a) and concentrated aqueous nitric acid solution (Tabazadeh et al., 2002b) droplets. These analyses bring forth new and interesting ideas on where freezing initiates in supercooled drops. However, we propose the importance of surface-initiated nucleation in the atmosphere remains unknown for three main reasons: 1) Evaluation of thermodynamic criteria for water-ice phase changes does not demonstrate a preference for surface nucleation in supercooled water. 2) Though laboratory data analysis suggest a role for surface nucleation, nucleation rate measurements to directly test this hypothesis in an air ambient are not available. 3) Surface (Tabazadeh et al., 2002a) and volume nucleation rates (Pruppacher, 1995) cannot be distinguished with atmospheric observations of deeply supercooled water (Sassen and Dodd, 1988; Heymsfield and Miloshevich, 1993, 1995; Rosenfeld and Woodley, 2000; Field et al., 2001).

\section{Theoretical and thermodynamic justification}

\subsection{Theoretical basis}

In the adopted classical formulation used by Tabazadeh et al. (2002a,b), nucleation rates are the product of (1) an exponential function involving the free energy barrier for embryo formation and (2) a pre-exponential factor (the "attack frequency"). The formulations and numerical values of both terms depend on the initiation process. The dimensionality of a surface nucleation process will strongly affect both the thermodynamics and kinetics of the freezing. Therefore, we distinguish between a two-dimensional surface nucleation and a near-surface formation of a three-dimensional embryo. 


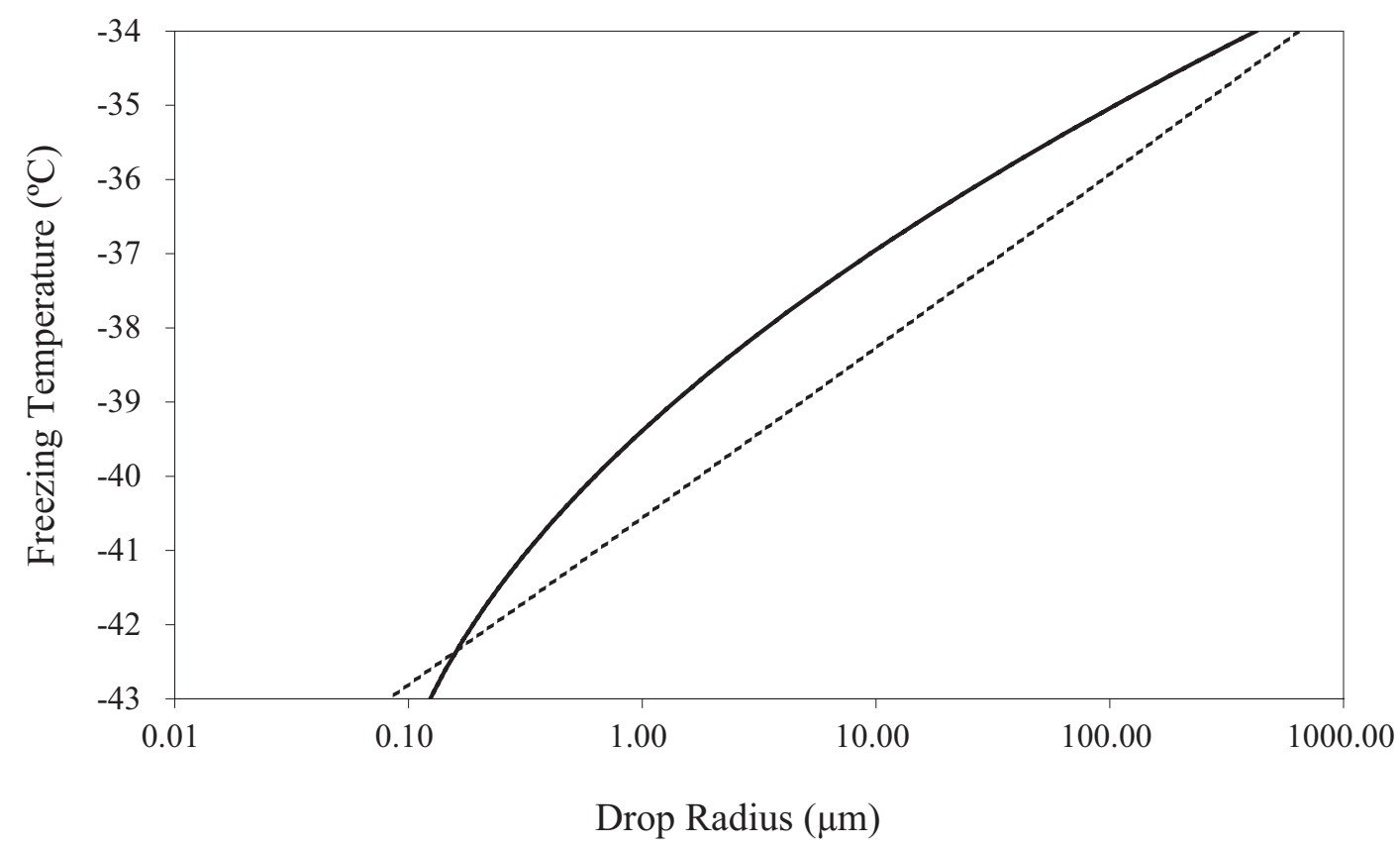

- - J J (Tabazadeh et al., 2002a)

- $\mathrm{J}_{\mathrm{V}}$ (Pruppacher, 1995)

Fig. 1. Estimated freezing temperature $\left(\mathrm{J}=1 \mathrm{~s}^{-1}\right.$ ) as a function of drop radius for surface (Js (Tabazadeh et al., 2002a)) and volume ( $\mathrm{Jv}$ (Pruppacher, 1995)) nucleation.

The former is a genuinely two-dimensional process associated with the formation of a monolayer-thick film at the surface of a droplet. For this scenario, calculation of the free-energy barrier is complicated. The pre-exponential factor, which is proportional to the surface density of water molecules, also includes the rate of growth of the monolayerthick critical embryo. At this point, it is impossible to predict nucleation rates for this truly two-dimensional process. Therefore, we do not discuss this possibility.

The latter, considered in the theoretical discussions of Tabazadeh et al. (2002a,b), is simply three-dimensional nucleation occurring in a near-surface shell. In general, the probability of embryo formation is proportional to the volume of the liquid where nucleation takes place. Thus, for the near-surface nucleation scenario, the pre-exponential factor is proportional to the volume of the shell, while in the case of volume nucleation, the pre-exponential factor is proportional to the volume of the entire droplet. If $R_{c}$ is a typical size of the critical embryo and $R_{d}$ is the droplet radius, the ratio of the attack frequencies for near-surface and volume nucleation is $R_{c} / R_{d}$, or less than $10^{-3}$ for a micron-size droplet. This small ratio indicates that the rate of a near-surface nucleation process is only comparable with that of classical volume nucleation if the energy of a critical embryo at the surface of a droplet is significantly lower than the energy of a similar embryo formed in the bulk. We are unaware of any convincing evidence for such a large free energy difference.

\subsection{The imperfect wetting criterion}

One basic thermodynamic criterion for evaluating where nucleation initiates is the "wetting criterion". For surface nucleation to dominate, wetting should not occur or be imperfect. In other words, the surface tension of a solid-vapor interface $\left(\sigma_{s v}\right)$ minus the surface tension of a replaced liquid-vapor interface $\left(\sigma_{l v}\right)$ must be less than the surface tension of a solidliquid interface $\left(\sigma_{s l}\right), \sigma_{s l}+\sigma_{l v}-\sigma_{s v}>0$. Several well-known results have been brought in to support surface nucleation via the imperfect wetting criterion (Tabazadeh et al., 2002a,b). However, we believe that this literature has been misrepresented.

First, Tabazadeh et al. (2002a,b) use Cahn's results (Cahn, 1977) to imply that imperfect wetting is expected below the critical point $(647 \mathrm{~K}$ for water) and as a result, surface nucleation should be favored. In fact, Cahn argues that perfect wetting should be observed at a critical point and that a phase transition from perfect to imperfect wetting should take place at some temperature below the critical temperature. Cahn's argument does not imply that perfect wetting is improbable away from the critical point. Wetting transitions have nothing to do with critical points (Dietrich, 1988; de Gennes, 1985; Schick, 1990). Moreover, our everyday experience shows that saturated water vapor may condense on various substrates both in the form of droplets (no wetting) and as a thick liquid film (perfect wetting) at temperatures well below the critical temperature of $647 \mathrm{~K}$. 
Second, Tabazadeh et al. (2002a,b) use optical studies (Elbaum et al., 1993) to illustrate that the imperfect wetting criterion is met at $0^{\circ} \mathrm{C}$. Indeed, Elbaum's experiments completed in a vacuum reveal water forming a film of limited thickness on an ice surface at $0^{\circ} \mathrm{C}$ (i.e. imperfect wetting). However, there are two problems with using Elbaum et al. (1993) as support for surface-initiated homogeneous nucleation in our atmosphere. First, since surface energies are strong functions of temperature, experiments completed at $0^{\circ} \mathrm{C}$ cannot be used to evaluate wetting at $-40^{\circ} \mathrm{C}$. Elbaum and Schick (1991) predict the difference in surface energies $\left(\sigma_{s l}+\sigma_{l v}-\sigma_{s v}\right)$ at the triple point in a vacuum to be three orders of magnitude smaller than any of the individual surface energies. This tiny difference might change magnitude or sign between $0^{\circ} \mathrm{C}$ and $-40^{\circ} \mathrm{C}$. More importantly, when Elbaum's experiments were completed in air, the more relevant scenario for atmospheric applications, the water-ice interfaces exhibited complete wetting at $0^{\circ} \mathrm{C}$.

Direct evaluation of the imperfect wetting criterion at $-40^{\circ} \mathrm{C}$ is inconclusive. In general, reported values for surficial energies are found by fitting observed nucleation rates to the classical expression for volume-based nucleation. If we ignore this logical inconsistency, direct evaluation using experimental values suggests the imperfect wetting criterion may be met, but the evidence is not compelling. When experimental value extrapolations (and uncertainties) are evaluated at $-40^{\circ} \mathrm{C}$ (Pruppacher and Klett, 1997), the interface energy between ice and air $\left(\sigma_{s v}\right)$ varies from $102-111 \mathrm{~mJ} \mathrm{~m}^{-2}$ depending on the crystallographic orientation, the surface tension of water $\left(\sigma_{l v}\right)$ is approximately $87 \mathrm{~mJ} \mathrm{~m}^{-2}$, and the interface energy between ice and water $\left(\sigma_{s l}\right)$ varies experimentally from $15-25 \mathrm{~mJ} \mathrm{~m}^{-2}$.

In addition, interfacial free energies only equal their asymptotic values $\left(\sigma_{s l}, \sigma_{l v}, \sigma_{s v}\right)$ when all three phases have macroscopic dimensions. For near-surface nucleation, the ice embryo and the thickness of a liquid layer separating ice embryo facets from the vapor phase are microscopic. Therefore, surface tensions associated with a wet ice-vapor interface depend on the microscopic thickness of the liquid layer separating the embryo and the vapor phase. In this case, the free energy can only be computed by taking into account long-range van der Waals intermolecular forces. These forces are known, for example, to determine the interfacial energies in the case of surface melting (Dash et al., 1995). For a small embryo, even computing the free energy of a dry facet requires consideration of the long-range potential of surrounding water.

Finally, we wish to comment on the theoretical discussion (Dijkaev et al., 2002) cited by Tabazadeh et al. (2002 a,b), that describes newly formed ice embryos as a tiny compact crystals having equilibrium crystal shape with two types of facets. This picture of the embryo is not consistent with current understanding of the ice initiation process. A critical nucleus is a strongly non-equilibrium object and at temperatures of homogeneous nucleation, consists of only tens of molecules. Recent molecular dynamic simulations (Matsumoto et al., 2002) have shown that a critical nucleus in water is a non-compact, chain-like object. Moreover, even if we assume that a nucleus is compact, its shape will have nothing in common with the equilibrium shape at corresponding temperatures. The growth drive at the ice-water interface would rapidly destroy any emergent facets in a process called kinetic roughening.

\section{Re-analysis of laboratory data}

Re-analysis of laboratory data by Tabazadeh et al. (2002a,b) suggests both surface and volume nucleation may occur in laboratory experiments. Though volume ice nucleation rates from nitric acid solutions differ by four orders of magnitude, these experimental data collapse to within one order of magnitude when expressed as a surface rate. In addition, two of the data sets, which show the thermodynamically perplexing result of decreasing nucleation rates at lower temperatures, have flatter nucleation rates when plotted as surface rates. Compiled nucleation rates also indicate that freezing can initiate on the surface or in the volume of supercooled water drops. Volume-initiated nucleation is indicated by similar nucleation rates/nucleation rate slopes despite a large range in droplet radii. When volume-initiated rates are replotted as surface-initiated rates, they exhibit more scatter (e.g. measurements made in heptane grease + sorbitan tristearate for drop sizes ranging from 3-300 $\mu \mathrm{m}$, Taborek, 1985). On the other hand, surface-initiated nucleation is indicated by measurements that exhibit variability in nucleation rates/nucleation rate slopes with different droplet sizes and ambients. When one reported volume nucleation rate (measurements made in heptane grease + sorbitan trioleate for drop sizes ranging from 3-65 $\mu \mathrm{m}$, Taborek, 1985) is plotted as a surface-initiated rate, it falls on a straighter line. Indeed, these interesting observations imply surface nucleation may be a freezing mechanism in laboratory experiments.

Unfortunately, many of the quoted laboratory measurements have been made with an oil/surfactant ambient (e.g. Taborek, 1985), not an air ambient. As plotted in Tabazadeh et al. (2002a), nucleation rate measurements in an air ambient (DeMott and Rogers, 1990) for a small range of drop sizes (radius of approximately $5 \mu \mathrm{m}$ ) do not exhibit scatter in either the volume or the surface domain. Nucleation rate measurements made as a function of drop size in an air ambient could help determine if freezing rates are a function of available volume or surface area. These measurements could help reveal the importance of surface nucleation in our atmosphere.

\section{Atmospheric relevance}

At present, the most atmospherically relevant comparison is between Pruppacher (1995) volume nucleation rates and 


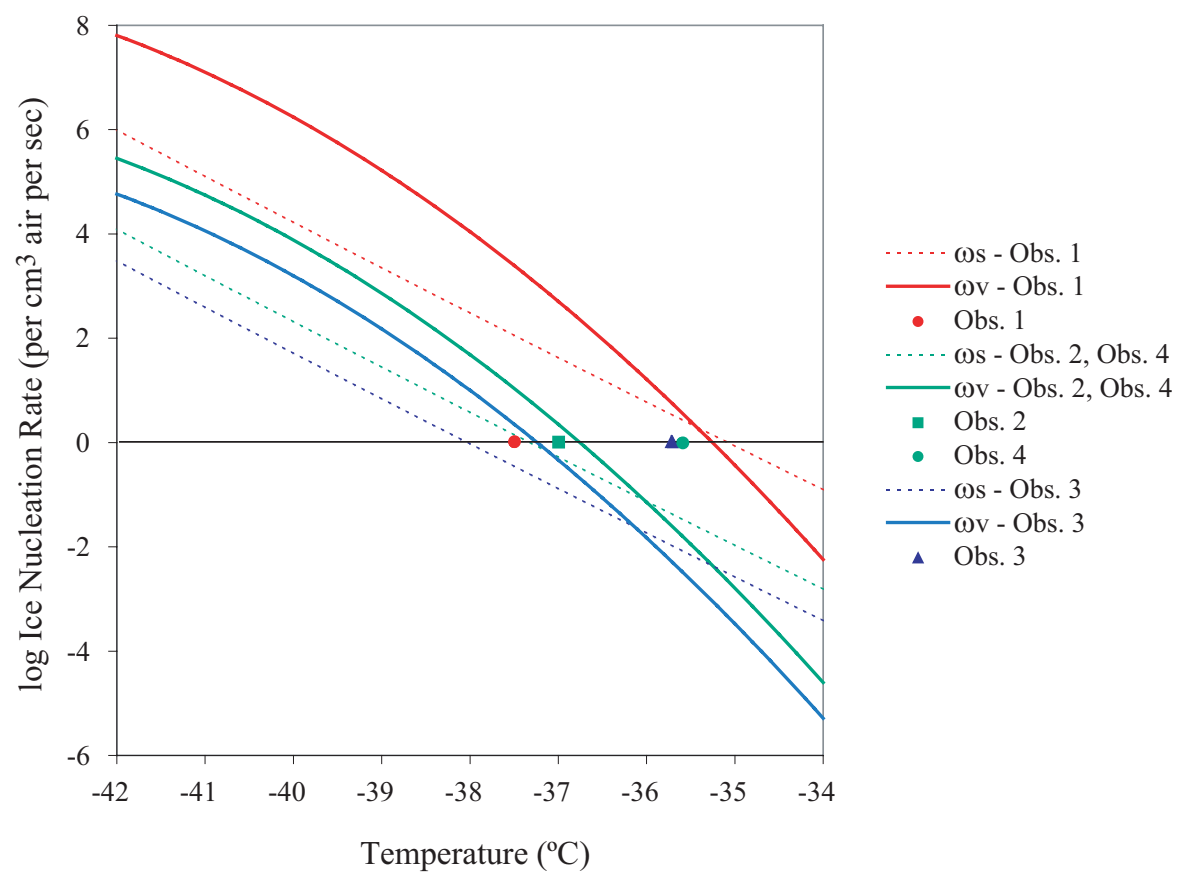

Fig. 2. Atmospheric observations (Table 1) and freezing temperature predictions (i.e. solid line at $\mathrm{J}=1 \mathrm{~s}^{-1}$ ) based on parameterizations of surface $\left(\omega_{S}=J S * S A\right.$ (Tabazadeh et al., 2002a)) and volume $\left(\omega_{v}=J v * V\right.$ (Pruppacher, 1995)) nucleation rates. It is not possible to distinguish between surface and volume nucleation on the basis of these atmospheric measurements. We used a monodisperse size distribution in these calculations. DeMott and Rogers (1990) measured a polydisperse population of drops.

Table 1. Aircraft observations of freezing

\begin{tabular}{llll}
\hline Observation reference & $\begin{array}{l}\text { Drop radius } \\
\mu \mathrm{m}\end{array}$ & $\begin{array}{l}\text { Drops per } \\
\mathrm{cm}^{-3} \text { air }\end{array}$ & $\begin{array}{l}\text { Temperature } \\
{ }^{\circ} \mathrm{C}\end{array}$ \\
\hline 1. Rosenfeld and Woodley (2000) & 8.5 & 700 & -37.5 \\
2. Heymsfield and Miloshevich (1995) & 3 & 70 & -37 \\
3. Heymsfield and Miloshevich (1993) & 2.5 & 25 & -35.7 \\
4. Sassen and Dodd (1988) & 2.5 & 100 & -35.6 \\
\hline
\end{tabular}

Tabazadeh et al. (2002a) surface nucleation rates. In this comparison, the pre-exponential term of the nucleation rates represent differing molecular densities (volume nucleation proportional to drop volume vs. 2D surface nucleation proportional to drop surface area). In addition, both free energy terms are based on nucleation rate measurements made in air (DeMott and Rogers, 1990). Above $0.2 \mu \mathrm{m}$, volume nucleation rates predict higher freezing temperatures than surface nucleation rates (Fig. 1).

Atmospheric dynamics (e.g. updraft velocities) and droplet composition play important roles in the freezing of supercooled drops in our atmosphere. This fact makes simple comparisons between atmospheric observations and laboratory-parameterized nucleation rates difficult, and somewhat unsatisfying. Indeed, our calculations indicate that it is not possible to distinguish between surface and volume nucleation on the basis of published atmospheric measurements (Table 1, Fig. 2). Both volume nucleation theory (Pruppacher, 1995) and surface nucleation rates (Tabazadeh et al., 2002a) predict higher freezing temperatures than atmospheric observations of $17 \mu \mathrm{m}$-sized water droplets at $-37.5^{\circ} \mathrm{C}$ (Rosenfeld and Woodley, 2000). On the other hand, both volume nucleation theory (Pruppacher, 1995) and surface nucleation rates (Tabazadeh et al., 2002a) predict lower freezing temperatures than observations of 5 to $7 \mu \mathrm{m}$-sized droplets freezing at temperatures ranging from -35.6 to $-36^{\circ} \mathrm{C}$ (Sassen and Dodd, 1988; Heymsfield and Miloshevich, 1993; Field et al., 2001). Approximately $6 \mu \mathrm{m}$-sized droplets observed by Heymsfield and Miloshevich (1995) froze at temperatures in between the freezing temperatures 
predicted by surface and volume nucleation rates. While deep supercooling $\left(-40.7^{\circ} \mathrm{C}\right)$ of unactivated haze droplets have been suggested (Heymsfield and Miloshevich, 1993), these observations are limited by the water detection capabilities of a Rosemount icing probe (detection threshold $0.002 \mathrm{~g} \mathrm{~m}^{-3}$, Heymsfield and Sabin, 1989) and should not be used as evidence for surface nucleation.

\section{Conclusions}

For the past 50 years, homogeneous nucleation rates have been based on ice embryo formation in the volume of supercooled drops. However, the potential for ice embryo formation at the surface of atmospheric drops cannot be proven or eliminated using existing experimental, thermodynamic, or atmospheric data. We support Tabazadeh (2003)'s plea for more measurements of nucleation rates. In particular, nucleation rate measurements for a range of particle sizes in an air ambient (e.g., in experimental setups such as Möhler et al., 2003; Wood et al., 2002) would help clarify an active research question: where does freezing initiate in supercooled water droplets?

Acknowledgements. JEK thanks the University of Washington's Department of Earth and Space Sciences Peter Misch Fellowship for funding; MB and JEK thank NSF-ATM-02-1147 for funding; and we all thank T. Koop, T. Peter, A. Gillespie, and D. Hegg for discussions that helped shape this comment.

\section{References}

Cahn, J. W.: Critical point wetting, J. Chem. Phys., 66:8, 36673672, 1977.

Dash, J. G., Fu, H., and Wettlaufer, J. S.: The premelting of ice and its environmental consequences, Reports on Progress in Physics, 58:1, 115-167, 1995.

De Gennes, P. G.: Wetting: statics and dynamics, Reviews of Modern Physics, 57:3, 827-864, 1985.

DeMott, P. J. and Rogers., D. C.: Freezing nucleation rates of dilute solution droplets measured between $-30^{\circ} \mathrm{C}$ and $40^{\circ} \mathrm{C}$ in laboratory simulations of natural clouds, J. Atmos. Sc., 47:9, 10561064, 1990.

Dietrich, S.: Wetting phenomena, in Phase Transitions and Critical Phenomena, eds. C. Domb and J. Lebowitz, Vol. 12, Academic Press, London, 1988.

Dijkaev, Y. S., Tabazadeh, A., Hamill, P., and Reiss, H.: Thermodynamic conditions for the surface-stimulated crystallization of atmospheric droplets, J. Phys. Chem. A, 106: 10247-10253, 2002 .

Elbaum, M. and Schick, M.: Application of the theory of dispersion forces to the surface melting of ice, Phys. Rev. Lett., 66:13, 1713-1716, 1991.

Elbaum, M., Lipson, S. G., and Dash., J. G.: Optical study of surface melting on ice, J. Crystal Growth, 129: 3-4, 491-505, 1993.
Field, P. R., Cotton, R. J., Noone, K., Glantz, P., Kaye, P. H., Hirst, E., Greenaway, R. S., Jost, C., Gabriel, R., Reiner, T., Andreae, M., Saunders, C. P. R., Archer, A., Choularton, T., Smith, M., Brooks, B., Hoell, C., Bandy, B., Johnson, D., and Heymsfield, A.: Ice nucleation in orographic wave clouds: Measurements made during INTACC, Quart. J. Met. Soc., 127:575, 1493-1512, 2001.

Heymsfield, A. J. and Sabin, R. M.: Cirrus crystal nucleation by homogeneous freezing of solution droplets, J. Atmos. Sc., 46:14, 2252-2264, 1989.

Heymsfield, A. J. and Miloshevich, L. M.: Homogeneous ice nucleation and supercooled liquid water in orographic wave clouds, J. Atmos. Sc., 50, 2335-2353, 1993.

Heymsfield, A. J. and Miloshevich, L. M.: Relative humidity and temperature influences on cirrus Formation and evolution: $\mathrm{Ob}$ servations from wave clouds and FIRE II, J. Atmos. Sc., 52:23, 4302-4326, 1995.

Matsumoto, M., Saito, S., and Ohmine, I.: Molecular dynamics simulation of the ice nucleation and growth process leading to water freezing, Nature, 416, 409-413, 2002.

Möhler, O., Stetzer, O., Schaefers, S., Linke, C., Schnaiter, M., Tiede, R., Saathoff, H., Krämer, M., Mangold, A., Budz, P., Zink, P., Schreiner, J., Mauersberger, K., Haag, W., Kärcher, B., and Schurath, U.: Experimental investigation of homogeneous freezing of sulphuric acid particles in the aerosol chamber AIDA, Atmos. Chem. Phys., 3, 211-223, 2003.

Pruppacher, H. R.: A new look at homogeneous ice nucleation in supercooled water drops, J. Atmos. Sc., 52:11, 1924-1933, 1995.

Pruppacher, H. R. and Klett, J. D.: Microphysics of Clouds and Precipitation. Kluwer Academic Publishers, Dordrecht, The Netherlands, 1997.

Rosenfeld, D. and Woodley, W.: Deep convective clouds with sustained supercooled liquid water down to $-37.5^{\circ} \mathrm{C}$, Nature, 405 , 440-442, 2000.

Sassen, K. and Dodd, G. C.: Homogeneous nucleation rate for highly supercooled cirrus cloud droplets, J. Atmos. Sc., 45:8, 1357-1369, 1988.

Schick, M.: Introduction to wetting phenomena, in Liquids at Interface, Charvolin, J., Joanny, J. F., and Zinn-Justin, J. (Eds), Elsevier, 1990

Tabazadeh, A.: Commentary on "Homogeneous nucleation of NAD and NAT in liquid stratospheric aerosols: insufficient to explain denitrification" by Knopf et al., Atmos. Chem. Phys., 3, 863865, 2003.

Tabazadeh, A., Djikaev, Y. S., and Reiss, H.: Surface crystallization of supercooled water in clouds. Proceedings of the National Academy of Sciences of the USA, 99:25, 15 873-15 878, 2002a.

Tabazadeh, A., Djikaev, Y. S., Hamill, P., and Reiss, H.: Laboratory evidence for surface nucleation of solid polar stratospheric cloud particles, J. Phys. Chem. A, 106, 10 238-10 246, 2002 b.

Taborek, P.: Nucleation in emulsified supercooled water, Physical Review B, 32:9, 5902-5906, 1985.

Wood, S. E., Baker, M. B., and Swanson, B. D.: Instrument for studies of homogeneous and heterogeneous ice nucleation in freefalling supercooled water droplets, Review of Scientific Instruments, 73:11, 3988-3996, 2002. 